\title{
COMPARATIVE STUDY ON SOLAR PHOTOVOLTAIC PANEL FOR DIFFERENT SLOPE ANGLES
}

\author{
S. Irfan Sadaq ${ }^{1}$, Dr. Syed Nawazish Mehdi ${ }^{2}$, Greeshma Ravi ${ }^{3}$ and Sankalp Milin ${ }^{4}$
}

\begin{abstract}
The use of solar photovoltaic electricity generation had become an effective way to exploit the sun's energy as well as reduce saddle on the power grid. The main purpose of this project is to analyze different types of commercially available solar panels presented for Hyderabad's climatic conditions especially at the exact coordinates of SUES Campus, Hyderabad. The analysis entitles determining the performance of each panel at different slope angles at various times in a year. The target here is to obtain the most efficient panel for a solar powered setup on the campus.
\end{abstract}

Keywords: Radiations, Solar Photovoltaic Cells, Mono-Crystalline, Poly-Crystalline, Declination.

\section{INTRODUCTION}

Many years ago, the demands in usage of energy have become more and more for which they dig out of the ground. In $17^{\text {th }}$ century, almost all energies came from wood, water and wind. All these energy sources came from the sun, since solar energy drove wind and rain, grew trees, and grew crops to nourish our animals and ourselves.

Energies are renewable until the earth last, this is because of sun. the use of fossil fuel has increased for which there is a need to shift for alternative energies.

\section{a. Renewable and Alternative Energy Sources}

Renewable energy sources are energy supplies that are refilled by natural processes at least as fast as we use them. All renewable energy comes, ultimately, from the sun. We can use the sun directly (as in solar heating systems) or indirectly (as in hydroelectric power, wind power, and power from biomass fuels).

b. Types of Renewable and Alternative Energy.

There are several renewable energy sources that are in use today.

- Solar energy

- Geothermal power

- Hydropower

- Ocean thermal energy conversion

- Wind energy

- Biomass

c. Types of Solar Cells

Solar cells are classically named after the semiconducting material. These materials have characteristics of absorb sunlight. Some cells are designed for working on the earth and some are in space. They are made from silicon crystal (mono-crystalline) fig.1 and some are cut from a block of silicon crystals (poly-crystalline) Fig.2.

\footnotetext{
${ }^{1}$ Mechanical Engineering Department, Muffakham Jah College of Engineering and Technology, Hyderabad, Telangana, India

2

3

${ }_{3}$ Mechanical Engineering Department, Muffakham Jah College of Engineering and Technology, Hyderabad, Telangana, India

${ }^{4}$ Mechanical Engineering Department, Muffakham Jah College of Engineering and Technology, Hyderabad, Telangana, India
} 


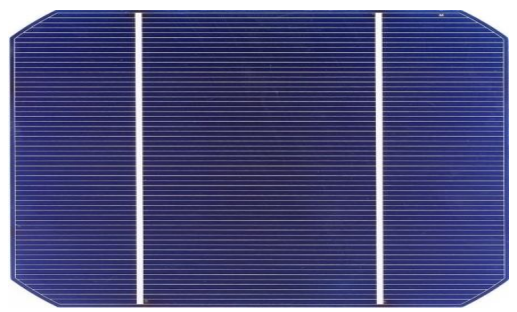

Fig.1: Monocrystalline Solar Cell

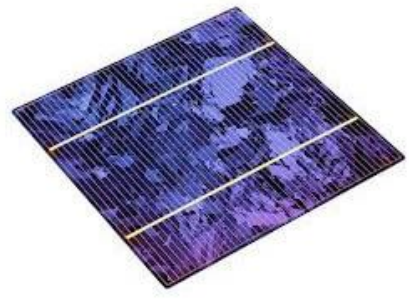

Poly-Crystalline Solar Cell

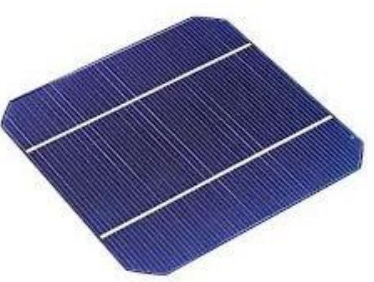

Mono-Crystalline Solar Cell

Fig.2: Polycrystalline Solar Cell

\section{LITERATURE SURVEY}

Solar cell is an electronic device which converts suns energy in electrical energy. The principal behind is it once sun rays fall on the cell it produces current and voltage and finally produces electricity [1]. The material present in the panel absorb the light raises to generate high energy electrons later due to the moments in these electrons across the solar cell circuit. There may be different materials for converting suns energy into electrical energy. The present work evaluate the concept over solar radiation properties for determining the optimum tilt angle and the yield of power station [2] for maximum power generation in SPV plants based on the different case studies carried in Jordan University of Science and Technology by using calculation and simulation approaches. Focuses on the intensity of solar radiation for converting solar energy into heat energy based on latitude and whether a condition of different places [3].

In the present works authors [4] developed a methodologies and techniques for reducing the reducing the cost of the SPV plants for upcoming generation keeping in view of the rapid growth in population as SPV plays a crucial role in large generation of solar power. Performance of SPV panel is depend on the climatic conditions and the amount of solar radiations incident on the panel / collector [5] as the efficiency of the panel reduces because of dust particles, birds droppings and air pollutions. Renewable energy resources are growing quickly, many design approaches were developed in large scales for achieving the overall efficiency of the panels [6]. Authors in their paper developed a standard procedure for designing a $20 \mathrm{kVA}$ mini-grid connected SPV systems using PV modules across the array fields in Kenya [7] and 1MW grid connected SPV in large scale at Nkrumah University of Science and Technology (KNUST), Ghana[8]. 


\section{SOLAR RADIATION CALCULATIONS}
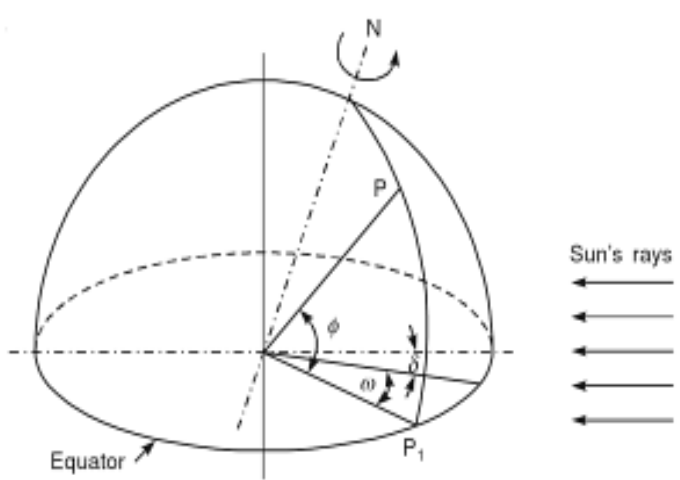

Fig.3: Solar Radiation Angles (Courtesy [10])

Solar radiation varies in intensity at different locations on the earth which revolves elliptically around the sun as shown in fig.3. For the calculations of solar radiation, the position of point $\mathrm{p}$ on the earth's surface with regard to sun ray's can be located. If the latitude $\varnothing$, the hour angle $\omega$ for the point and the sun's declination $\delta$ are known

a. Formulae [10]

DECLINATION ANGLE:

$s=23.45 \sin \left[\frac{360}{365}(284+n)\right]$

BEAM RADIATION:

DIFFUSE RADIATION:

$$
R_{b}=\frac{\cos \theta}{\cos \theta}=\frac{\sin \theta \sin (\theta-\beta)+\cos \theta \cos \omega \cos (\phi-\beta)}{\sin \phi \sin \theta+\cos \phi \cos \theta \cos \omega}
$$

REFLECTED RADIATION:

$$
R_{d}=\frac{1+\cos \theta}{2}
$$

$$
R_{r}=\frac{\rho(1-\cos \beta)}{2}
$$

TOTAL RADIATION:

The total radiation flux falling on an inclined surface at any instant is expressed as:

EFFICIENCY:

$$
I_{T}=I_{b} R_{b}+I_{d} R_{d}+\left(I_{b}+I_{d}\right) R_{r}
$$

$$
\eta^{\prime}=\frac{E}{A^{*} I_{t} * P R}
$$

b. Sample Calculation

Case -1: Slope ( $\beta) 1^{0}$, Hour angle ( $\left.\omega\right)$ 11AM, $1^{\text {st }}-04-2017$, Banjara Hills, Hyderabad $(\phi=17.41$ Latitude).

$$
\begin{aligned}
& \mathrm{n}=82 \text { days } \\
& \delta=23.45 \sin \left[\frac{360}{365}(284+91)\right]=4.016^{\circ} \\
& \omega=15(11-12)=-15^{\circ} \\
& \beta=14^{\circ} \\
& \cos \theta=\sin \delta \sin (\phi-\beta)+\cos \delta \cos \omega \cos (\phi-\beta)=0.964 \\
& \cos \theta_{Z}=\sin \phi \sin \delta+\cos \phi \cos \delta \cos \omega=0.938 \\
& \eta_{b}=\frac{\cos \theta}{\cos \theta_{I}}=1.027 \\
& r_{d}=\frac{1+\cos \beta}{2}=0.985 \\
& r_{\gamma}=\frac{\rho(1-\cos \beta)}{2}=0.0148 \\
& I_{T}=I_{b} R_{b}+I_{d} R_{d}+\left(I_{b}+I_{d}\right) R_{r}=1038.39 \mathrm{w} / \mathrm{m}^{2}
\end{aligned}
$$


$\eta=\frac{E}{A * I_{T} * P R}=5.07$

\section{EXPERIMENTAL ANALYSIS}

For our experimental analysis as shown in fig. 4 we took into consideration two solar panels, i.e., Monocrystalline and Polycrystalline Solar Cells. The testing of these panels was carried out on the first day of April. To obtain desired slopes, we first calculated the heights at which each panel was supposed to be positioned while resting on the surface. Using trigonometric laws, the heights were evaluated, and subsequently blocks of wood were measured and crafted in order to help support the panel at the required slopes. As for the connections, two wires were soldered at the positive and negative terminals of each panel while the other end was free to connect to the multimeter to note output readings. At every hour of the day and at three different slopes per hour, output voltage and current readings were noted. Further, Energy and Efficiency calculations were carried out.

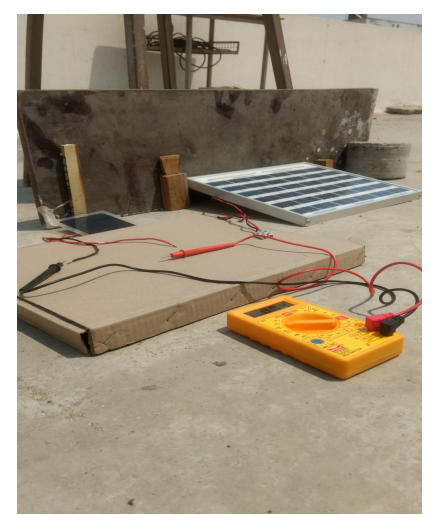

Fig.4: Experimental Setup

Table.1: Experimental Data obtained on April 1, 2017

\begin{tabular}{|c|c|c|c|c|c|c|c|c|c|}
\hline \multicolumn{5}{|c|}{ Date: April 1 ${ }^{\text {st }}, 2017$} & $\mathrm{n}=91$ & \multicolumn{2}{|c|}{$\mathbf{E}$} & \multicolumn{2}{|c|}{ Efficiency } \\
\hline Time & \multirow{2}{*}{\begin{tabular}{|c|} 
Slope \\
$14^{\circ}$ \\
\end{tabular}} & \multicolumn{2}{|c|}{$\begin{array}{c}\text { Monocrystalline } \\
\text { Voltage(V) } \\
\text { Current(A) }\end{array}$} & \multicolumn{2}{|c|}{$\begin{array}{c}\text { Polycrystalline } \\
\text { Voltage(V) } \\
\text { Current(A) }\end{array}$} & Mono & Poly & Mono & Poly \\
\hline \multirow{3}{*}{$\begin{array}{c}10: 00 \\
\text { AM }\end{array}$} & & 6.01 & 0.07 & 18.92 & 0.31 & 0.42 & 5.87 & 6.64 & 6.93 \\
\hline & $16^{\circ}$ & 6.06 & 0.09 & 19.06 & 0.32 & 0.55 & 6.10 & 8.68 & 7.18 \\
\hline & $18^{\circ}$ & 6.11 & 0.10 & 19.17 & 0.34 & 0.61 & 6.52 & 9.62 & 7.67 \\
\hline \multirow{3}{*}{$\begin{array}{c}11: 00 \\
\text { AM }\end{array}$} & $14^{\circ}$ & 6.06 & 0.06 & 19.51 & 0.40 & 0.36 & 7.80 & 5.07 & 8.20 \\
\hline & $16^{\circ}$ & 6.10 & 0.08 & 19.63 & 0.41 & 0.49 & 8.05 & 6.88 & 8.44 \\
\hline & $18^{\circ}$ & 6.18 & 0.10 & 19.72 & 0.43 & 0.62 & 8.48 & 8.69 & 8.87 \\
\hline \multirow{3}{*}{$\begin{array}{c}12: 00 \\
\text { PM }\end{array}$} & $14^{\circ}$ & 6.11 & 0.12 & 19.28 & 0.48 & 0.73 & 9.25 & 9.91 & 9.37 \\
\hline & $16^{\circ}$ & 6.13 & 0.13 & 19.30 & 0.49 & 0.80 & 9.46 & 10.83 & 9.56 \\
\hline & $18^{\circ}$ & 6.14 & 0.13 & 19.37 & 0.50 & 0.80 & 9.69 & 10.80 & 9.77 \\
\hline \multirow{3}{*}{$\begin{array}{l}\text { 1:00 } \\
\text { PM }\end{array}$} & $14^{\circ}$ & 6.04 & 0.09 & 19.04 & 0.41 & 0.54 & 7.81 & 7.61 & 8.21 \\
\hline & $16^{\circ}$ & 6.08 & 0.10 & 19.17 & 0.42 & 0.61 & 8.05 & 8.57 & 8.44 \\
\hline & $18^{\circ}$ & 6.19 & 0.12 & 19.32 & 0.46 & 0.74 & 8.89 & 10.37 & 9.30 \\
\hline \multirow{3}{*}{$\begin{array}{c}2: 00 \\
\text { PM }\end{array}$} & $14^{\circ}$ & 6.00 & 0.07 & 18.93 & 0.30 & 0.42 & 5.68 & 6.64 & 6.70 \\
\hline & $16^{\circ}$ & 6.06 & 0.08 & 19.10 & 0.32 & 0.48 & 6.11 & 7.57 & 7.19 \\
\hline & $18^{\circ}$ & 6.09 & 0.10 & 19.21 & 0.35 & 0.61 & 6.72 & 9.62 & 7.91 \\
\hline
\end{tabular}

\section{RESULTS AND DISCUSSIONS}

After performing the experimentation and theoretical analysis the results obtained are tabulated in table 1 and the suitable graphs are shown in fig. 5 to fig. 8 . 


\section{Declinational Angle}

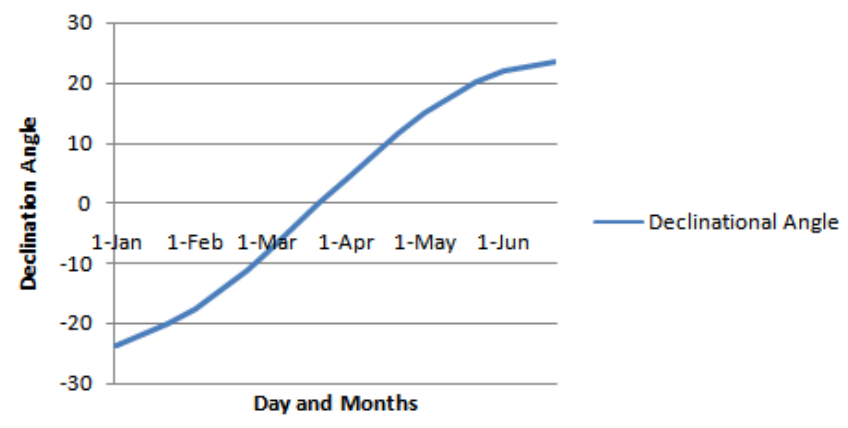

Fig.5: Declination Angle for a period of 6months in 2017.

Date vs. Irradiation

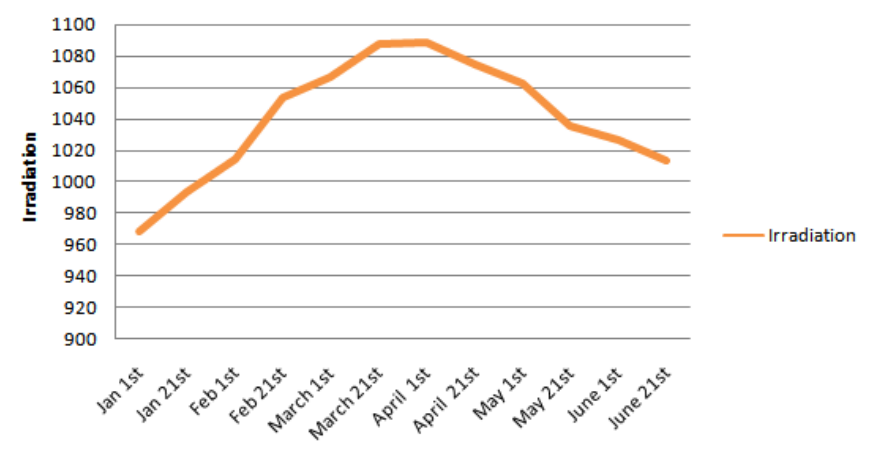

Fig.6: Graph representing the Date vs. Irradiation

As the highest radiation value is occurring on the $1^{\text {st }}$ of April, we considered that day for our experimental analysis.

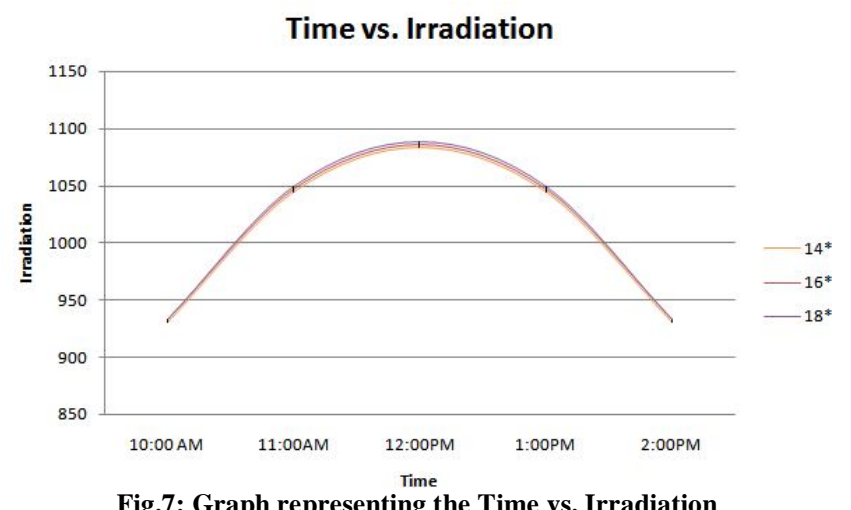

Fig.7: Graph representing the Time vs. Irradiation

Slope vs. Efficiency

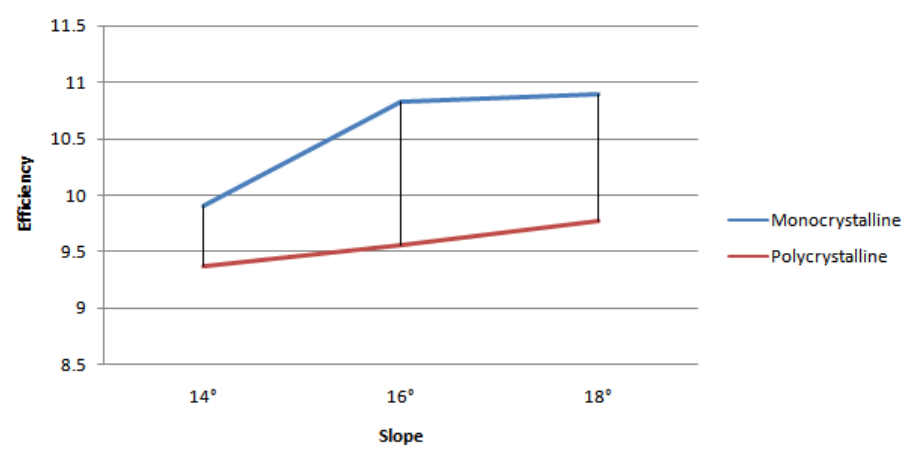

Fig.8: Graph representing the Slope vs. Efficiency Obtained from Experimentation 


\section{CONCLUSION}

Based on theoretical calculations along with experimental analysis the following conclusion are obtained for SUES Campus.

- It is generally advised that the tilt of the panel should be close to the latitude angle $(\Phi)$. Therefore, through our experimental analysis we have determined that the optimum slope for our location should be $18^{\circ}$ till the month of April and $14^{\circ}$ from May for extracting maximum radiation from the sun.

- Monocrystalline and Polycrystalline are the most popular commercially available solar cells for large scale power generation. Monocrystalline solar cells have an efficiency that is $2 \%$ higher than Polycrystalline.

- Polycrystalline takes more space but is cheaper and more cost-effective for a large scale system. This is why we maximum use polycrystalline rather than Monocrystalline.

- Therefore, the system must utilize Polycrystalline type of solar cell at an optimum slope of $18^{0}$ for the best results till April and $14^{\circ}$ from May.

- A SPV system can play a significant role in achieving a green and clean environment.

\section{REFERENCES}

[1]. Askari Mohammad Bagher, Mirzaei Mahmoud Abadi Vahid, Mirhabibi Mohsen, "Types of Solar Cells and Application”, American Journal of Optics and Photonics, ISSN: 2330-8486 (Print); ISSN: 2330-8494 (Online), August 21, 2015, 3(5); 94-113.

[2]. Qais Azzam Khasawneh, Qatada Abdullah Damra, Omaymah Husni Bany Salman, "Determining the Optimum Tilt Angle for Solar Applications in Northern Jordan", Jordan Journal of Mechanical and Industrial Engineering (JJMIE), ISSN: 1995-6665, Volume9 Number3, June 2015; 187-193.

[3]. Imants Ziemells, Liene Kance vica, Zanis Jesko, Henriks Putans, "Calculation of Energy Produced by Solar Collector", Engineering for Rural Development, Jelgava, 28-29.05.2009.

[4]. Hemakshi Bhoye, Gaurang Sharma, “An Analysis of One MW Photovoltaic Solar Poer Plant Design”, IJAREEIC, ISSN(Print): 23203765, ISSN(Online): 2278-8875, Vol. 3, Issue 1, Jan 2014; 6969-6973.

[5]. Amit Kumar Mondal and Kamal Bansal, "Structural Analysis of Solar Panel Cleaning Robotic Arm", Technical Nores, Current Science, Vol. 108, No. 6, 25 March 2015; 1047-1052.

[6]. Ravindra Naik, Vinayakumar B. Melmari, Adarsh Adeppa, "Analysis and Optimization Solar Panel Supporting Structure Using FEM”, IJEIT, ISSN: 2277-3754, Volume 2, Issue 7, Jan 2013; 25-36.

[7]. Michael Juma Saulo, Victor Odhiambo Omondi, "Design and Analysis of Solar Energy Mini - Grid for Rural Electrification" Open Access Library Journal, 2: e1903. http://dx.doi.org/10.4236/oalib.1101903.

[8]. Ebenezer Nyarko Kumi, Abeeku Brew-Hammond, "Design and Analysis of 1MW Grid-Connected Solar PV System in Ghana", African Technology Policy Studies Network, ATPS 2013, ATPS Working Paper No. 78, ISBN: 978-9966-030-56-6.

[9]. Dr. Syed Nawazish Mehdi, Non Conventional Energy Sources.

[10]. Kothari D.P, Singal. K.C, Ranjan. Rakesh. Renewable Energy Sources and Emerging Technologies, PHI Publication

[11]. R.K Rajput, Non-conventional Energy Sources and Utilization (Energy Engineering), SChand Publications. 